\title{
Agroecologia e Gastronomia unidas pela busca da Segurança Alimentar e Nutricional: Um relato inicial das experiências de extensão
}

\author{
Luciano Majolo $^{l}$, Thiago Bernardino de Sousa Castro ${ }^{l}$, Wesley de Assis Silva ${ }^{l}$, Sabrina Bezerra Boulitreau ${ }^{l}$, Shirleyde
} Alves dos Santos $^{1 *}$, Thaylla Brito ${ }^{2}$

\author{
${ }^{1}$ Universidade Estadual da Paraíba; majolo.agroecologia@gmail.com; thiagopbpe@gmail.com; \\ wesleyanjospb@gmail.com; sabrinaboulitro@gmail.com; shirleyde.santos@gmail.com; ${ }^{2}$ Centro Universitário Mauricio \\ de Nassau; thayllacarollyne@gmail.com.
}

\begin{abstract}
RESUMO: O presente relato apresenta os primeiros contatos entre alunos do curso de bacharelado em Agroecologia da Universidade Estadual da Paraíba-UEPB e alunos da graduação em Gastronomia do Centro Universitário Mauricio de Nassau-UNINASSAU, iniciado no primeiro semestre de 2019 e vinculado ao projeto de extensão "Ações para a Segurança e Soberania Alimentar e Nutricional na Vila Florestal, Lagoa Seca/PB”. Buscamos demonstrar que a interdisciplinaridade é a chave para o desenvolvimento da extensão acadêmica, estabelecendo uma conexão entre essas áreas complementares, que juntas, dispõem de conhecimentos favoráveis para propor mudanças positivas dos costumes alimentares e culturais da sociedade. Resgatando e valorizando os sabores e saberes populares, ambicionamos utilizar o ambiente acadêmico e suas práticas de pesquisa e extensão como ferramentas de desenvolvimento da segurança alimentar e nutricional (SAN) aliada à conscientização ambiental, elegendo o conceito das Plantas Alimentícias Não Convencionais (PANC'S) e do Slow Food como estratégias para se atingir este objetivo. Objetivou-se possibilitar a conexão da prática acadêmica com a realidade da sociedade civil, de forma a contribuir efetivamente com a construção de um mundo mais justo, saudável e ambientalmente sustentável.
\end{abstract}

PALAVRAS-CHAVE: Interdisciplinaridade; PANC'S; Slow food; Sustentabilidade.

\section{CONTEXTO}

O atual quadro civilizatório urge por soluções que promovam a sustentabilidade tanto dos meios de produção, como dos padrões de consumo da sociedade. Se não temos o poder para mudar os rumos da política mundial e da economia capitalista, podemos despertar, através de pequenas ações, a transformação da consciência de alguns indivíduos para que estes se tornem agentes da preservação ambiental e autogestores da sua saúde (BOFF, 2017).

Buscando utilizar o ambiente acadêmico e suas práticas de pesquisa e extensão como ferramentas de desenvolvimento da segurança alimentar e nutricional (SAN) aliada à conscientização ambiental, elegeu-se o conceito das Plantas Alimentícias Não Convencionais (PANC'S) e do Slow Food como estratégias para se atingir este objetivo.

No Brasil, o conceito das PANC'S vem sendo discutido dentro do meio acadêmico a pouco mais de uma década, apesar de seu conteúdo remeter a práticas alimentares ancestrais e que hoje se encontram em desuso (KINUPP; LORENZI, 2014). A utilização de plantas não convencionais na alimentação, além de fornecer fontes alternativas de nutrientes preservando a biodiversidade, possui um importante valor como promotora de conscientização ambiental (OLIVEIRA et al., 2018). Segundo Kinupp (2007), as PANC'S possuem importante capacidade de complementação alimentar, diversificação de cardápios e fonte de renda familiar, sendo seu potencial econômico ainda pouco explorado.

O termo Slow Food foi criado por Carlo Petrini em 1986, sendo um movimento e organização não governamental que tem como objetivo proporcionar uma maior apreciação da comida, melhorar a qualidade das refeições e promover uma produção que valorize o produto, o produtor e o meio ambiente (OLIVEIRA, 2013). De acordo com Freitas (2014), o Slow Food é um movimento que defende a biodiversidade e as tradições alimentares em todo o planeta, buscando uma produção e consumo sustentáveis.

O perfil da sociedade contemporânea se apresenta em transformação, verificando-se, com a consolidação da globalização dos mercados, o surgimento de demandas para novos objetos de desejo, tais como produtos e práticas associadas à ideia de ruralidade: "os territórios rurais assumem um papel de grande relevância no mundo 'urbanizado' de hoje, o de prover uma variedade de bens e serviços para a população não rural, desejosa de se afastar temporária ou permanentemente das patologias da vida urbana" (CAVALCANTI, 2004; SALES, 2016).

Partindo destes princípios teóricos, iniciou-se, dentro do curso de bacharelado em Agroecologia da Universidade Estadual da Paraíba-UEPB, no primeiro semestre de 2019, um projeto de extensão intitulado "Ações para a Segurança e Soberania Alimentar e Nutricional na Vila Florestal, Lagoa Seca/PB”, vinculado ao Núcleo de Extensão Rural Agroecológica (NERA) e em parceria com o curso de graduação em Gastronomia do Centro Universitário Mauricio de Nassau-UNINASSAU. Buscamos demonstrar que a interdisciplinaridade é a chave para o desenvolvimento da extensão acadêmica, estabelecendo uma ligação entre essas áreas complementares, que juntas, dispõem de conhecimentos favoráveis para propor mudanças positivas dos costumes alimentares e culturais da sociedade. Objetivou-se possibilitar a conexão da prática acadêmica com a realidade da sociedade civil, de forma a contribuir efetivamente com a construção de um mundo mais justo, saudável e ambientalmente sustentável.

Caderno Verde de Agroecologia e Desenvolvimento Sustentável (ISSN 2358-2367) v. 9, n.7, e-6981, 2019 doi: $10.18378 /$ cvads.v9i7.6981 
MAJOLO, L. et al. Agroecologia e Gastronomia unidas pela busca da Segurança Alimentar e Nutricional: um relato inicial das experiências de extensão. In: II Congresso Paraibano de Agroecologia \& IV Exposição Tecnológica, 2019. Anais... Caderno Verde de Agroecologia e Desenvolvimento Sustentável, Pombal, v. 9, n.7, e-6981, 2019.

\section{DESCRIÇÃO DA EXPERIÊNCIA}

Os encontros entre os alunos dos cursos de Agroecologia-UEPB e Gastronomia-UNINASSAU proporcionaram a aproximação entre as experiências vivenciadas em seus respectivos eixos de pesquisa, como uma forma de complementação interdisciplinar dos conteúdos até então estudados. Foram organizadas diferentes reuniões, em ambos os câmpus universitários, sendo sempre os anfitriões responsáveis por conduzir as atividades.

O primeiro encontro foi realizado no campus II, CCAA-UEPB, no mês de abril de 2019, servido como um momento de apresentação e contato inicial dos participantes. Além de uma palestra introdutória sobre o conceito das PANC'S, o encontro serviu para apresentar as propostas do projeto de extensão "Ações para a Segurança Alimentar e Soberania Alimentar e Nutricional na Vila Florestal, Lagoa Seca/PB” e suas perspectivas para futuras ações. O campus II, CCAA-UEPB situa-se na zona rural de Lagoa Seca-PB, e é vizinho à comunidade Vila Florestal, que apresenta uma condição de vulnerabilidade socioeconômica, sendo negligenciada pelas políticas públicas municipais. O projeto desenvolvido junto à comunidade visa minimizar essas condições, implementando práticas de diferentes formatos e temáticas, como o uso das PANC'S e dos conceitos do Slow Food, entre outros.

O segundo encontro foi promovido nos ambientes da UNINASSAU - campus Estação Velha, no mês de maio de 2019. Buscando compartilhar as experiências acadêmicas dos alunos do curso de Gastronomia, abordou-se, através de recursos audiovisuais, as características da alimentação contemporânea e a importância que o ato de comer possui para a valorização de diferentes culturas, por meio das qualidades dos alimentos e da forma como são produzidos. Preservando a biodiversidade e fortalecendo os agricultores familiares, enfatizou-se a relação da Agroecologia com a Ecogastronomia e a importância de se ter consciência sobre cada processo da cadeia de produção gastronômica, desde a retirada do alimento do solo pelas mãos do(a) agricultor(a), até o preparo das refeições nos restaurantes ou domicílios. Enfatizou-se a importância de uma alimentação saudável e o respeito e a ética envolvidos durante todo o processo produtivo.

Segundo Philippi e Aquino (2015), a alimentação pode ser caracterizada como identidade cultural, pois através dela há um reconhecimento de sociedades, juntamente com os hábitos em torno da sua alimentação. Essa identidade cultural envolve práticas, costumes, representações, valores e linguagens de um povo, podendo indicar qual a relação entre um determinado grupo e o seu território no que se refere à sua alimentação e nutrição.

O terceiro encontro ocorreu no mês de junho de 2019, novamente no campus II, CCAA-UEPB. Desta vez o assunto debatido foi a Soberania Alimentar e a Segurança Alimentar e Nutricional (SAN), promovendo-se um debate aberto ao corpo discente da universidade. O diálogo abordou a importância da Agroecologia para a SAN e os mecanismos políticos, sociais e econômicos envolvidos na cadeia produtiva dos alimentos. Ao final do encontro foi oferecida a primeira experiência gastronômica do projeto, com a degustação de um bolo produzido com uma variedade crioula de batata-doce roxa (Ipomoea batatas (L.) Lam.), utilizando suas flores, folhas e raízes como ingredieentes, além de um suco de vinagreira (Hibiscus sabdariffa) com ora-pro-nóbis (Pereskia aculeata).

Esses encontros foram o ponto de partida para o projeto ganhar novos horizontes, como a preparação de uma horta para o plantio e cultivo de PANC'S dentro do campus II, CCAA-UEPB. Novas pesquisas e ações da extensão já estão em andamento e o caminho para outras conquistas e transformações foi apenas iniciado, com a perspectiva de gerar bons "frutos" num futuro por vir.

\section{RESULTADOS}

As primeiras reuniões e atividades serviram para reforçar as afinidades entre os conceitos e premissas de ambos os cursos, efetivando a interdisciplinaridade como recurso favorável ao desenvolvimento da extensão acadêmica. Tanto as propostas de pesquisa das PANC'S vinculada à Agroecologia, como do Slow Food dentro da Ecogastronomia, mostraram-se muito pertinentes para contribuir com a Soberania e Segurança Alimentar e Nutricional da comunidade Vila Florestal-PB. Reconhecemos nestes conteúdos respostas simples para a complementação nutricional da alimentação destas famílias além do fortalecimento de sua identidade regional.

Foi possível também identificar um interesse mútuo por parte dos(as) alunos(as) durante os encontros, percebendo-se a curiosidade por novos paradigmas ligados à alimentação. Os(as) alunos(as) se mantiveram abertos para contribuir com suas experiências e absorver as informações recebidas, proporcionando um ambiente favorável para a construção coletiva e participativa do conteúdo científico. Priorizou-se uma metodologia de ensino global e generalista, permitindo uma visão holística e mais completa daquilo que chamamos de alimento. Foi possível contemplar que desde o plantio até o beneficiamento ou preparo final de uma refeição, o alimento compõe uma cadeia complexa de relacionamentos, histórias e de inúmeras considerações éticas que são fundamentais para a construção de uma sociedade mais justa e sustentável.

\section{CONCLUSÃO}

Concluímos que as experiências estão sendo muito válidas, proporcionando novos conhecimentos e o aperfeiçoamento individual de todos(as) os(as) participantes. A metodologia participativa na construção do conhecimento mostrou-se muito eficaz para o aprendizado e o desenvolvimento das ações do projeto de extensão. 
MAJOLO, L. et al. Agroecologia e Gastronomia unidas pela busca da Segurança Alimentar e Nutricional: um relato inicial das experiências de extensão. In: II Congresso Paraibano de Agroecologia \& IV Exposição Tecnológica, 2019. Anais... Caderno Verde de Agroecologia e Desenvolvimento Sustentável, Pombal, v. 9, n.7, e-6981, 2019.

Concluímos que a interdisciplinaridade pode ser uma chave importante para a qualidade das ações extensionistas, fortificando a cooperação mútua e a interdependência nas relações humanas. A sociedade carece de conhecimentos científicos que forneçam benefícios práticos, principalmente à população mais carente e que muitas vezes se apresenta marginalizada pelo interesse público. Pequenas ações podem provocar grandes mudanças, e são a partir delas que faremos com que nosso mundo se torne um local mais confortável e agradável para todos. Entender que o ato de comer representa muito mais que apenas se alimentar, mas um ato social, cultural, político e econômico protegendo os diferentes povos é uma tarefa de essencial importância. Proporcionar a soberania e segurança alimentar e nutricional necessária para garantir a saúde daqueles (as) que estão próximos e ao nosso alcance é a premissa norteadora deste projeto e o relato aqui exposto apenas apresenta a fase inicial desta pretensão, que desde já ambiciona proporcionar de forma ética, o respeito, justiça e a sustentabilidade na nossa humanidade.

\section{REFERÊNCIAS}

BOFF, L. Saber cuidar: ética do humano-compaixão pela terra. Petrópolis, RJ: Vozes, 2017.

CAVALCANTI, J. S. B. Globalização e ruralidade. In: WANDERLEY, M. N. B. (Org.). Globalização e desenvolvimento sustentável: dinâmicas sociais rurais no nordeste brasileiro (pp. 17-32). São Paulo, SP: Polis. 2004.

FREITAS, J. L. de. Alimentação sustentável: uma revisão de literatura sobre SlowFood. 2014.42 f. Trabalho de Conclusão de Curso (Graduação em Nutrição) - Universidade Federal da Paraíba, João Pessoa. 2014.

KINUPP, V. F. Plantas alimentícias não-convencionais da Região Metropolitana de Porto Alegre, RS. 2007.562 f. Tese (Doutorado) - Programa de Pós-Graduação em Fitotecnia, Faculdade Agronomia, Universidade Federal do Rio Grande do Sul, Porto Alegre, 2007.

KINUPP, V. F; LORENZI, H. Plantas alimentícias não convencionais (PANC) no Brasil: guia de identificação, aspectos nutricionais e receitas ilustradas. São Paulo: Instituto Plantarum de Estudos da Flora, 2014. 768p.

OLIVEIRA, D. C. de. O slow food e a nova dimensão temporal da modernidade. Barbarói. Santa Cruz do Sul, n.39, p.216-234, jul./dez. 2013.4

OLIVEIRA, B. de; RAGUSE, M.; FRANCISCO, M. S. B.; OKAJIMA, Y.; HENTGES, T. I.; SILVEIRA, T. A. da. Operação taioba: o uso de plantas alimentícias não convencionais (PANC) e da agricultura urbana na construção do senso agroecológico de escolares da rede pública de São Leopoldo, RS. Cadernos de Agroecologia, v.13, n.1, 2018.

PHILIPPI, S. T.; AQUINO, R. de C. (orgs.) Dietética: Princípios para o planejamento de uma alimentação saudável. Barueri - SP: Manole, 2015.

SALES, F. L. A experiência gastronômica e a agroecologia: reflexões sobre um consumo contemporâneo. In. XIII Seminário Anual da Associação Nacional de Pesquisa e Pós-Graduação em Turismo 2016. Anais do Seminário da ANPTUR, 2016.

\section{AGRADECIMENTOS}

Apoio financeiro: Fundação de Apoio à Pesquisa do Estado da Paraíba - FAPESQ. 